radioisotopes should be discouraged since their results could repeatedly not be confirmed when a straightforward system to measure insulin pharmacokinetics was employed. ${ }^{45}$

We thank $\mathrm{K} J$ Klingebiel and $\mathrm{P}$ Könings for their valuable cooperation during the experiments and $\mathrm{C}$ Broermann for her excellent technical work.

${ }^{1}$ Klemp P, Staberg B, Madsbad S, Kolendorf K. Smoking reduces insulin absorption from subcutaneous tissue. Br Med $\mathcal{F}$ 1982;284:237.

2 Binder C. Absorption of injected insulin. Acta Pharmacol Toxicol (Copenh) $1969 ; 27$ (suppl 2):1-84.

${ }^{3}$ Berger M, Cüppers HJ, Hegner H, Jörgens V, Berchtold P. Absorption kinetics and biologic effects of subcutaneously injected insulin preparations. Diabetes Care 1982;5:77-91.

${ }^{4}$ Kemmer FW, Berchtold P, Berger M, et al. Exercise-induced fall of blood glucose unrelated to alteration of insulin mobilisation. Diabetes $1980 ; 28: 1131-7$.

${ }^{5}$ Cüppers HJ, Berchtold P, Berger M. Sauna-induced acceleration in insulin absorption? Br Med f 1982;281:307.

(Accepted 17 April 1984)

Department of Medicine E, University of Düsseldorf, West Germany

I MUHLHAUSER, MD, research assistant

H J CUPPERS, MD, senior registrar

$M$ BERGER, $M D$, professor of medicine

Correspondence to: $\mathrm{Dr}$ Ingrid Mühlhauser, Medizinische Klinik E Universität Düsseldorf, Moorenstrasse 5, 4000 Düsseldorf, West Germany.

\section{Unusual pulmonary reaction during short term prophylaxis with pyrimethamine-sulfadoxine (Fansidar)}

Fansidar (25 mg pyrimethamine and $500 \mathrm{mg}$ sulfadoxine) is a valuable alternative for treating chloroquine resistant falciparum malaria and is increasingly used for prophylaxis. The manufacturer claims that side effects are generally mild and transient. Serious reactions affecting the skin and mucous membranes, liver, and bone marrow have recently been reported, ${ }^{2}{ }^{2}$ but we describe here for the first time pulmonary adverse reactions during pyrimethaminesulfadoxine prophylaxis.

\section{Case report}

A 45 year old man with no history of allergic reactions travelled to Lima, Peru, on 14 October 1982, returning to Sweden four days later. He used pyrimethamine-sulfadoxine (Fansidar) 1 tablet/week for malaria prophylaxis from 29 September to 11 November. The day he left Peru he felt feverish and had a sore throat. After arrival in Sweden he was tired and had a temperature of $38^{\circ} \mathrm{C}$. He then developed cough and transient diarrhoea and from 24 October to 8 November was treated with doxycycline. On 8 November because of his persistent symptoms a chest $x$ ray examination was performed, which showed extensive, subpleural, localised, confluent alveolar infiltrates in the periphery of the lungs. The central parts were normal. Treatment was changed to erythromycin, but this was stopped after six days because it had no effect, and the patient was admitted to hospital on 16 November. Physical examination, including auscultation of the lungs, showed no abnormalities. A second chest radiograph, 10 days after the first, showed slight progression of the pulmonary infiltrates. Laboratory findings were as follows: erythrocyte sedimentation rate $85 \mathrm{~mm}$ in the first hour, haemoglobin $12.6 \mathrm{~g} / \mathrm{dl}$, white blood cell count $8.9 \times 10^{9} / 1$ with $72 \%$ neutrophils and $6 \%$ eosinophils, C reactive protein positive, antinuclear factors not detected. Liver function tests (normal range within brackets) showed bilirubin $6 \mu \mathrm{mol} / \mathrm{l}(4-22 \mu \mathrm{mol} / \mathrm{l})$, aspartate aminotransferase $2.8 \mu \mathrm{kat} / \mathrm{l}(<0.70 \mu \mathrm{kat} / \mathrm{l})$, alanine aminotransferase $3.74 \mu \mathrm{kat} / 1(<0.70 \mu \mathrm{kat} / \mathrm{l})$, and lactate dehydrogenase $7 \cdot 3 \mu \mathrm{kat} / 1(3 \cdot 9-8 \cdot 0 \mu \mathrm{kat} / \mathrm{l})$. Throat cultures showed $\beta$ haemolytic streptococci group A; other cultures were negative. Microscopical examination of sputum, for tuberculosis and parasites, and of stools was negative. Serological tests for various bacteria, viruses, or funguses also yielded negative results.

In view of the throat culture findings we treated him for seven days with phenoxymethylpenicillin. His temperature of $38{ }^{\circ} \mathrm{C}$ persisted until four days after the end of treatment. During his stay in hospital the serum aminotransferase activities rose slightly; the eosinophil count rose to $9 \%$ and the absolute eosinophil count from 300 to $600 \times 10^{6} / 1$. The subsequent course was uneventful and he was discharged on 3 December. Chest $x$ ray findings returned to normal in early January 1983, as did all laboratory values except for aminotransferase activities, which remained abnormal until early May.

\section{Comment}

Various sulphonamides may cause acute pulmonary reactions with fever and transient eosinophilia. Chest radiographs show segmental or diffuse micronodular pulmonary infiltrations. ${ }^{3} 4$ Most reports, however, have dealt with a combination of trimethoprim and sulfamethoxazole. $^{5}$ Up to November 1983 no similar pulmonary symptoms attributed to pyrimethamine-sulfadoxine were known to the Swedish adverse drug reactions advisory committee. After submitting this report, however, we learnt that one similar case had been reported to the manufacturers of Fansidar in January 1984.

The timing of the symptoms in our patient together with the signs of an allergic reaction suggested that pyrimethamine-sulfadoxine caused the pulmonary reaction and the increase in aminotransferase activities. The patient was not taking any other drugs and the results of extensive microbiological and serological examinations were negative. Definite proof would, however, have required rechallenge with pyrimethamine-sulfadoxine, which we considered unethical.

An increasing number of travellers visit areas where chloroquine resistant falciparum malaria is endemic and where pyrimethaminesulfadoxine is the drug of choice for malaria prophylaxis. We want to warn that pulmonary reactions might be caused by this drug.

1 Westergaard OW, Loft $S$, Dencker CK. Serious reactions during malaria prophylaxis with pyrimethamine-sulfadoxine. Lancet 1982 ;i :994.

2 Whitfield D. Presumptive fatality due to pyrimethamine-sulfadoxine. Larcet $1982 ;$;i : 1272 .

${ }^{3}$ Davies DM. Textbook of adverse drug reactions. Oxford: Oxford University Press, 1981.

- Meyler L, Herxheimer A. Side effects of drugs. Amsterdam: Elsevier, 1980.

${ }^{5}$ Finlayson WB, Johnson G. Multisystem toxicity after co-trimoxazole. Lancet 1978;ii:682-3.

(Accepted 7 March 1984)

Department of Infectious Diseases, Roslagstull Hospital, Karolinska Institute, Stockholm, Sweden

M SVANBOM, MD, physician

L ROMBO, MD, physician

Department of Clinical Pharmacology, Huddinge Hospital, Karolinska Institute, Stockholm, Sweden

L GUSTAFSSON, MD, clinical pharmacologist

Correspondence to: Dr Maj Svanbom, Department of Infectious Diseases, Roslagstull Hospital, Box 5651, S-114 89 Stockholm, Sweden.

\section{Bilateral vocal cord paralysis due to whiplash injury}

Whiplash injuries to the neck are common but they rarely cause major disabilities. We describe a patient who developed bilateral vocal cord paralysis and bilateral lateral rectus palsies after an acceleration injury to her neck-two complications of the whiplash syndrome not previously reported.

\section{Case report}

A 65 year old woman was admitted to hospital in January 1982 after the rear of her car had been struck by another vehicle. She was wearing a seatbelt and did not strike her head but she did sustain a severe whiplash injury to her neck followed by transient loss of consciousness lasting several minutes. Her immediate symptoms were neck and chest pain and diplopia. She had tachycardia (112 beats/min), stridor, weak phonation, and neurological examination showed bilateral sixth nerve palsies. Skull and chest radiographs were normal, but radiographs of the cervical spine showed congenital fusion of the second and third vertebrae. There was no displacement or bone injury and the odontoid process was intact.

She was given a soft collar and admitted for observation. A full ophthalmological examination confirmed bilateral lateral rectus palsies, more pronounced on the left side than the right. Because of the persistent stridor, difficulty in coughing, and weak voice, a laryngoscopy was also performed. This showed the vocal cords to be immobile in the paramedian plane. Examination of the pharynx and postnasal space showed them to be normal. 
After the patient was discharged from hospital there was little improvement in her speech and she developed increasing dyspnoea on minimal exertion accompanied by stridor. Laryngoscopy 18 months after her accident again showed failure of both vocal cords to abduct from the midline and so a tracheostomy was performed to relieve the symptoms. She also awaits corrective surgery for the diplopia.

\section{Comment}

This patient's neurological complications, bilateral sixth and tenth cranial nerve lesions, undoubtedly resulted from a whiplash injury. It is difficult to be certain, however, of either the mechanism or the sites of damage. Shearing and stretching forces within the skull, particularly in a downward direction, are thought to occur in acceleration injuries of the neck ${ }^{1}$ and may cause the abnormalities of consciousness and brainstem function sometimes associated with the whiplash syndrome. ${ }^{23}$ It may be relevant that both cranial nerves are at risk from such forces, the sixth nerve as it arches over the apex of the petrous bone and the tenth nerve within the jugular foramen. There was no evidence of ninth or eleventh cranial nerve damage, and this seems unusual since they also leave the skull through the jugular foramen. The persistence of cranial nerve lesions for two years suggests complete loss of continuity of the nerve trunks with probable associated damage to major nutrient arteries. In such circumstances spontaneous recovery of function is negligible. ${ }^{4}$ The brief loss of consciousness immediately after the whiplash injury supports clinical and experimental evidence that stresses induced by movements of the head are sufficient to cause injuries to the brain and that contact is not essential. 5

Although our patient's major symptoms of difficulty in breathing, coughing, and speaking have been helped considerably by tracheostomy, she continues to have mild vertebrogenic complaints. At each outpatient attendance she has always had tachycardia which we attribute to unopposed sympathetic action on her heart.

We thank Mrs Jenny Allen, district librarian, for providing a computerised literature search and reference material.

1 Forsyth HF. Extension injuries of the cervical spine. $\mathcal{F}$ Bone foint Surg [Am] $1964 ; 46: 1792-7$.

${ }^{2}$ Fisher CM. Whiplash amnesia. Neurology $1982 ; 82: 667-8$.

${ }^{3}$ Rowe J, Carlson C. Brainstem auditory evoked potentials in postconcussion dizziness. Arch Neurol 1980;37:679-83.

- Sunderland S. Nerves and nerve injuries. Edinburgh: Churchill Livingstone, 1972.

5 Adams JH, Gennarelli TA, Graham DI. Brain damage in non-missile head injury: observations in man and subhuman primates. In: Smith WT, Cavanagh JB, eds. Recent advances in neuropathology. Edinburgh: Churchill Livingstone, 1982:165-90.

(Accepted 17 April 1984)

Department of Rheumatology and Rehabilitation, Christchurch Hospital, Christchurch, Dorset BH23 2JX

M HELLIWELL, MRCP, senior registrar in rheumatology

Salisbury General Infirmary, Salisbury, Wiltshire SP2 7SX

J C ROBERTSON, DCH, MRCP, consultant rheumatologist

G B TODD, FRCs, consultant ear, nose, and throat surgeon

$M$ LOBB, FRCS, consultant ophthalmic surgeon

\section{Rhabdomyolysis in elderly people after collapse}

Severe rhabdomyolysis, sometimes leading to acute renal failure, may complicate coma from many causes including carbon monoxide poisoning, drug intoxication, ketoacidosis, and myxoedema. ${ }^{2}$ Ischaemic pressure necrosis of muscle may occur simply from prolonged awkward posture. ${ }^{3}$ After a stroke or an accidental fall old people often remain on the floor undiscovered for long periods, yet rhabdomyolysis is rarely recognised. We report a prospective study of muscle injury in such patients.

\section{Patients, methods, and results}

We studied all patients over 65 admitted to hospital in a four month period after collapsing and remaining on the floor for at least one hour.

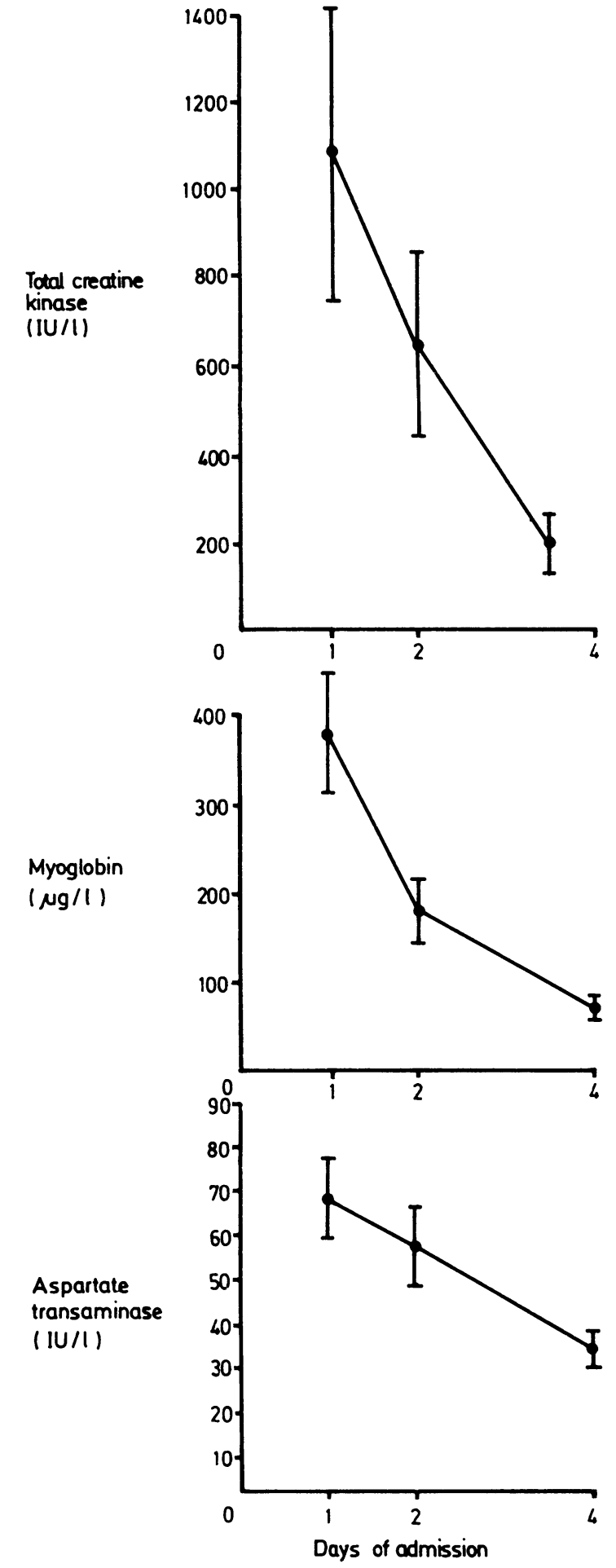

Mean serum myoglobin concentrations and activity of creatine kinase and aspartate transaminase in all patients.

Serum was taken for analysis of creatinine and myoglobin concentrations and serum aspartate transaminase and creatine kinase activities on days 1,2 , and 4 of admission. Urine was obtained on the same days. The concentration of myoglobin was measured by radioimmunoassay (RIA, United Kingdom), and creatine kinase activity by the optimised standard N-acetyl-L-cysteine method (Boehringer Mannheim) at $37^{\circ} \mathrm{C}$. Patients underwent serial electrocardiography, and those with raised serum muscle enzyme activity underwent $99 \mathrm{~m}$ Tc pyrophosphate scintigraphy of heart and skeletal muscle. Of the 18 patients studied (three men and 15 women, mean age 78 ), eight had suffered acute stroke, nine had fallen accidentally, and one had taken an overdose of triazolam. On admission eight were fully conscious, eight were drowsy, and two responded only to pain.

The figure shows the mean results for all patients. Sixteen had raised serum myoglobin concentrations (up to $1070 \mu \mathrm{g} / \mathrm{l}$ ) on day one, a mean (SD) of 17 (4) hours after discovery. In eight control patients (old people admitted to hospital acutely ill) serum myoglobin concentrations were within the normal range $(8-80 \mu \mathrm{g} / \mathrm{l})$ quoted by the kit manufacturer. Myoglobinuria could not be 